\title{
Confidence modeling with reliability: a systems approach to sustainable energy planning
}

\author{
Xiaosheng Qin ${ }^{1,2^{*}}, Y e \mathrm{Xu}^{3}$ and Jianjun $Y u^{4}$
}

\begin{abstract}
Background: Energy systems planning has played a strong role in setting up the framework for developing long-term policies of energy activities to help guide the future of a local, regional or national energy system. However, the planning process is complicated with a variety of uncertainties and complexities. In this study, a fuzzy confidence model coupled with mixed-integer programming was proposed for regional energy systems planning.

Results: Application of the model to a hypothetical case indicated that the model was capable of handling uncertainties expressed as fuzzy sets and taking capacity-expansion issues of energy facilities into consideration. The solutions from the proposed model could meet system constraints at different confidence levels, where each confidence level was further associated with different reliability scenarios.

Conclusions: The proposed model could help decision makers analyze the trade-offs between system economy and reliability, and explore cost-effective energy systems planning strategies under uncertainty.
\end{abstract}

Keywords: Fuzzy programming, Mixed-integer programming, Energy, Uncertainty

\section{Background}

It has been widely accepted that the task of energy systems planning process involves a variety of social, economic, environmental, technical, and political factors that are characterized with temporal and spatial variabilities (Cai et al. 2009). The system is further complicated by the existence of uncertainties that may be associated with the planning processes. Previously, a number of inexact optimization techniques were developed for assisting in the formulation of energy management plans and generation of optimal decision schemes (Liu et al. 2000; Cai et al. 2009; Lin and Huang, 2009). Among various alternatives, the fuzzy chance-constrained programming (FCCP) was advantageous in dealing with optimization problems subject to fuzzy constraints at prescribed confidence levels (Liu and Iwamura, 1998). In recent years, FCCP was successfully used in many environmental management fields (Cao et al. 2009). However, its application in energy systems planning field was very limited. Moreover, a FCCP

\footnotetext{
* Correspondence: xsqin@ntu.edu.sg

${ }^{1}$ School of Civil \& Environmental Engineering, Nanyang Technological

University, 50 Nanyang Avenue 639798 Singapore

${ }^{2}$ Earth Observatory of Singapore (EOS), Nanyang Technological University,

50 Nanyang Avenue 639798 Singapore

Full list of author information is available at the end of the article
}

model is incapable of handling the binary-decision (i.e. yes/no) problems which is important in energy systems planning for seeking solutions to capacity-expansion or operation-scheduling issues. To fill this gap, this study aims to develop a double-sided fuzzy chance-constrained mixed-integer programming (DFCCMIP) model for supporting regional energy systems planning under uncertainty. A hypothetical case will be used for demonstration.

\section{Energy systems planning model}

A regional energy system planning system, modified from Li et al. (2010), is to be investigated. Within the energy system, multiple energy sources are considered and various power conversion technologies are applied to generate the electricity from the provided energy sources. Generally, large-scale conversion technologies are responsible for conventional energy resources, and small-scale plants are based on local availability of renewable resources ( $\mathrm{Li}$ et al. 2010). The generated electricity will be used to meet the requirement of multiple end-users including industrial, commercial, agricultural, transportational and residential sectors. For environmental protection, the generated air pollutants from power conversion plants should be mitigated by different treatment technologies in order to meet the related emission standards. The decision maker is 
responsible for allocating energy resources/services from multiple facilities to multiple end-users at a minimum system cost within a multi-period time horizon in light of environmental constraints and uncertainties.

It is assumed that the end-users' electricity demands can be described as triangular fuzzy sets. Over the three planning periods (each one has 5 years), the demand amounts are $(50,70,96),(85,112,147)$ and $(135,170,200) \times 10^{3}$ GWh, respectively. The peak load demands are considered as deterministic, being 1.5, 2.0, $2.5 \mathrm{GW}$ in three periods, respectively. Totally, five energy sources (i.e., coal, natural gas, hydropower, wind, solar and nuclear) are used for power generation. Over three planning periods, the supplied costs of coal are $2.5,3$ and $3.5\left(\times 10^{3} \$ / \mathrm{TJ}\right)$, respectively; those for natural gas are 5, 5.5 and $6\left(\times 10^{3} \$ / \mathrm{TJ}\right)$, respectively; those for electricity are 900, 1000 and 1100 $\left(\times 10^{3} \$ / G W h\right)$, respectively. In order to meet the increasing energy demand from the end-users, capacity expansions of energy-supply facilities are necessary. Based on $\mathrm{Li}$ et al. (2010), the existing capacities of the coal-fired, gas-fired, hydropower, wind power, solar power and nuclear power conversion technologies are set as 10, 2.2, 2.8, 0, 0, 0 (GW), respectively. Other related parameters associated with the expansion options are listed in Table 1.

Sulfur dioxide $\left(\mathrm{SO}_{2}\right)$, nitrogen oxides $\left(\mathrm{NO}_{\mathrm{x}}\right)$ and particulate matter (PM) are the main pollutants emitted from power plants. To achieve the related environmental targets, each emission source has installed various mitigation measures to avoid penalties from government. The applied control techniques mainly include: (i) soda ash scrubber (SAS), wet limestone scrubber (WLS) and lime spray dryer (LSD) for reducing the $\mathrm{SO}_{2}$ amounts; (ii) Selective catalytic reduction (SCR) and selective non-catalytic reduction (SNCR) for controlling $\mathrm{NO}_{\mathrm{x}}$ emissions; (iii) Fabric filiter/baghouse $(\mathrm{BH})$, electrostatic precipitator (ESP) and wet collector (WC) for mitigating the PM emissions (Li et al. 2010). The treatment efficiencies of various technologies, the allowable emission amounts of power plants, and design safety coefficients for energy supply are also described by triangular fuzzy sets (see Table 2).

\section{Model Formulation}

Double-sided fuzzy chance-constrained programming (DFCCP) was firstly proposed by Fiedler et al. (2006). In a DFCCP model, constraints with fuzzy variables can be satisfied at a series of predetermined confidence levels with two reliability scenarios, i.e. the minimum and maximum reliabilities. The model could eventually be converted into two crisp equivalents for solution. The related solution algorithms could be referred to Fiedler et al. (2006). In addition, expansion of facility capacity in energy systems planning is necessary in order to meet the increasing energy demand over the planning horizons. Mixed integer linear
Table 1 Parameters related to power conversion technologies

\begin{tabular}{llll}
\hline Conversion technology & \multicolumn{3}{l}{ Time period } \\
\cline { 2 - 4 } & $\boldsymbol{t}=\mathbf{1}$ & $\boldsymbol{t}=\mathbf{2}$ & $\boldsymbol{t}=\mathbf{3}$ \\
\hline $\begin{array}{l}\text { Power generation cost } \\
\text { technology }\end{array}$ (10 $\left./ G W h\right)$ and operating time $(h)$ of conversion \\
Coal-fired power & $5.0\left(24900^{*}\right)$ & $5.5(24900)$ & $6.0(24900)$ \\
Gas-fired power & $4.5(24600)$ & $5.0(24600)$ & $5.5(24600)$ \\
Hydropower & $4.0(21000)$ & $4.5(21000)$ & $5.0(21000)$ \\
Wind power & $2.5(15000)$ & $3.0(15000)$ & $3.5(15000)$ \\
Solar power & $2.0(15000)$ & $2.5(15000)$ & $3.0(15000)$ \\
Nuclear power & $10.0(24600)$ & 11.0 & $12.0(24600)$
\end{tabular}

Fixed $\left(\$ 10^{6}\right)$ and variable $\left(\$ 10^{6} / \mathrm{GW}\right)$ costs for capacity expansion

$\begin{array}{llll}\text { Coal-fired power } & 325\left(700^{* *}\right) & 385(750) & 445(800) \\ \text { Gas-fired power } & 300(650) & 350(700) & 400(750) \\ \text { Hydropower } & 700(1800) & 770(1900) & 840(2000) \\ \text { Wind power } & 800(1900) & 880(1950) & 960(2000) \\ \text { Solar power } & 900(2000) & 990(2100) & 1080(2200) \\ \text { Nuclear power } & 1000(1950) & 1100(2100) & 1200(2250)\end{array}$

Variable upper bounds for capacity expansion (GW)

$\begin{array}{llll}\text { Coal-fired power } & 6.5 & 4.5 & 2.5 \\ \text { Gas-fired power } & 4.8 & 5.8 & 6.8 \\ \text { Hydropower } & 2.5 & 3.5 & 4.5 \\ \text { Wind power } & 0.8 & 1.8 & 2.8 \\ \text { Solar power } & 1.8 & 2.8 & 3.8 \\ \text { Nuclear power } & 2.5 & 3.5 & 4.5\end{array}$

Energy consumption per units of electricity production (TJ/GWh) $\begin{array}{llll}\text { Coal-fired power } & 12.5 & 12.4 & 12.3\end{array}$

$\begin{array}{llll}\text { Gas-fired power } & 11.5 & 11.4 & 11.3\end{array}$

$\begin{array}{llll}\text { Hydropower } & 4.0 & 3.95 & 3.9\end{array}$

$\begin{array}{llll}\text { Wind power } & 0.13 & 0.12 & 0.11\end{array}$

$\begin{array}{llll}\text { Solar power } & 5.0 & 4.9 & 4.8\end{array}$

$\begin{array}{llll}\text { Nuclear power } & 13.0 & 12.8 & 12.6\end{array}$

Available amounts of renewable energy $\left(10^{3} \mathrm{TJ}\right)$

Hydropower $\quad 90000 \quad 90000 \quad 90000$

$\begin{array}{lll}\text { Wind power } & 15000 & 15000\end{array}$

Solar power $20000 \quad 20000 \quad 20000$

Nuclear power $\quad 150000 \quad 150000 \quad 150000$

Notes: data are modified from Li et al. (2010); ${ }^{*}$ is the operating time for conversion technology; ${ }^{* *}$ is the variable costs for capacity expansion.

programming (MILP) is a useful tool (through using $0-1$ integer variables) to help determine whether or not a particular facility development or an expansion option needs to be undertaken (Huang et al. 1995). Coupling DFCCP and MILP into a general framework, a double-sided fuzzy chance-constrained mixed-integer 
Table 2 Parameters related to pollution control technologies

Pollution control technology Time period

Treatment cost of $\mathrm{SO}_{2}$ emission (\$/tonne)

$\begin{array}{llll}S A S & 55 & 57 & 59 \\ W L S & 45 & 48 & 51 \\ \text { LSD } & 30 & 33 & 36\end{array}$

Treatment cost of $\mathrm{NO}_{x}$ emission (\$/tonne)

$\begin{array}{llll}S C R & 55 & 59 & 62 \\ S N C R & 35 & 38 & 40\end{array}$

Treatment cost of PM emission ( $\$ /$ tonne)

$\begin{array}{llll}\text { BH } & 135 & 140 & 145 \\ \text { ESP } & 125 & 133 & 140 \\ \text { WC } & 115 & 125 & 135\end{array}$

Allowable emission amounts of pollutants (tonne)

$\begin{array}{llll}\mathrm{SO}_{2} & (40,44,50)^{*} & (61,72,81) & (69,82,93) \\ \mathrm{NO}_{x} & (20,32,45) & (31,47,61) & (35,57,80) \\ P M & (0.3,0.52,0.7) & (0.45,0.8,1.1) & (0.49,0.89,1.2)\end{array}$

Treatment efficiency of pollutants (\%)

SAS

$(0.85,0.91,0.99)$

WLS

$(0.76,0.82,0.9)$

$\angle S D$

$(0.7,0.77,0.85)$

$S C R$

$(0.8,0.86,0.9)$

$S N C R$

$(0.5,0.62,0.7)$

BH

$(0.96,0.975,0.99)$

ESP

WC

$(0.95,0.964,0.98)$

$(0.94,0.958,0.97)$

Notes: data are modified from Li et al. (2010); * $(a, b, c)$ represents a triangular fuzzy set, where $a$ and $c$ are the minimum and the maximum possible values, and $b$ is the most likely value.

programming (DFCCMIP) model can be formulated as follows (Li et al. 2010):

$$
\begin{aligned}
\text { Minf }= & \sum_{t=1}^{T}\left(C E C_{t} * X C_{t}+C E N_{t} * X G_{t}\right)+\sum_{t=1}^{T} C I E_{t} * X E_{t} \\
& +\sum_{i=1}^{I} \sum_{t=1}^{T} C V_{i t} * X W_{i t}+\sum_{i=1}^{I} \sum_{t=1}^{T}\left(Y_{i t} * A_{i t}+B_{i t} * X_{i t}\right) \\
& +\sum_{i=1}^{I} \sum_{o=1}^{O} \sum_{t=1}^{T} C S_{o t} * X S_{i o t}+\sum_{i=1}^{I} \sum_{p=1}^{P} \sum_{t=1}^{T} C N_{p t} * X N_{i p t} \\
& +\sum_{i=1}^{I} \sum_{q=1}^{Q} \sum_{t=1}^{T} C P_{q t} * X P_{i q t}
\end{aligned}
$$

Subject to:

(1)Constraints for mass balance of fossil fuels:

$$
X W_{1 t} * F E_{1 t} \leq X C_{t}, \forall t
$$

$X W_{2 t} * F E_{2 t} \leq X G_{t}, \quad \forall t$

(2)Constraints for availabilities of energy resources:

$X W_{i t}{ }^{*} F E_{i t} \leq U P_{i t}, \forall t$ for $i \geq 3$

(3)Constraints for electricity supply and demand balance:

$\operatorname{Pos}\left\{\tilde{\alpha}_{l}, \tilde{d}_{t} \mid \tilde{\alpha}_{l} \sum_{i=1}^{I}\left(X W_{i t}+X E_{t}\right) \geq \tilde{d}_{t}\right\} \geq \beta_{l}, \forall t$

(4)Constraints for electricity generation of every power conversion technology:

$$
\left(\sum_{t^{\prime}=1}^{t} X_{i t^{\prime}}+R C_{i}\right) * S T_{i t} \geq X W_{i t}, \forall i, t
$$

(5)Constraints for electricity peak load demand:

$$
\sum_{i=1}^{I} R C_{i}+\sum_{i=1}^{I} \sum_{t^{\prime}=1}^{t} X_{i t^{\prime}} \geq V_{t}, \forall t
$$

(6) Constraints for capacity expansion of electricitygeneration facilities:

$Y_{i t}\left\{\begin{array}{l}=1, \text { if capacity expansion is undertaken } \\ =0, \text { if otherwise }\end{array}, \forall i, t\right.$

$X_{i t} \leq M_{i t}{ }^{*} Y_{i t}, \forall i, t$ 
(7)Constraints for air pollution control demand:

$$
\begin{aligned}
& \sum_{o=1}^{O} X S_{i o t}=W_{i t}{ }^{*} I N S_{i t}, \forall i, t \\
& \sum_{p=1}^{P} X N_{i p t}=W_{i t}{ }^{*} I N N_{i t}, \forall i, t \\
& \sum_{q=1}^{Q} X P_{i q t}=W_{i t}{ }^{*} I N P_{i t}, \quad \forall i, t
\end{aligned}
$$

(8)Constraints for air pollutants emissions:

$$
\begin{aligned}
& \operatorname{Pos}\left\{\tilde{\eta}_{o}, \quad \tilde{E S_{t}} \mid \sum_{i=1}^{I} \sum_{o=1}^{O}\left(1-\tilde{\eta}_{o}\right) X S_{i o t} \leq E S_{t}\right\} \geq \beta_{l}, \forall t \\
& \operatorname{Pos}\left\{\tilde{\eta}_{P}, \quad \tilde{E N_{t}} \mid \sum_{i=1}^{I} \sum_{p=1}^{P}\left(1-\tilde{\eta}_{p}\right) X N_{i p t} \leq E N_{t}\right\} \geq \beta_{l}, \forall t \\
& \operatorname{Pos}\left\{\tilde{\eta}_{q}, \quad \tilde{E P_{t}} \mid \sum_{i=1}^{I} \sum_{q=1}^{Q}\left(1-\tilde{\eta}_{q}\right) X P_{i q t} \leq E P_{t}\right\} \geq \beta_{l}, \forall t
\end{aligned}
$$

(9)Non-negative constraints:

$$
X C_{t}, X G_{t}, X E_{t}, X W_{i t}, X_{i t} \geq 0, \forall i, t
$$

where $f$ is expected system cost for energy system management over the planning horizon $\left(\$ 10^{9}\right) ; i$ is type of power conversion technology, $i=1,2, . ., I$ (in this study, $I$ is considered as 6 , where $i=1,2, \ldots, 6$ means the coal, natural gas, hydropower, wind power, solar power and nuclear power, respectively); $o$ is type of $\mathrm{SO}_{2}$ control measure, $o=1$, $2, \ldots, O ; p$ is type of $\mathrm{NO}_{\mathrm{x}}$ control measure, $p=1,2, \ldots, P ; q$ is type of PM control measure, $q=1,2, \ldots, Q ; O, P$ and $Q$ are numbers of control measure of the pollutants, respectively; $t$ is time period, $t=1,2$,.., $T$; $t^{\prime}$ is an intermediate index satisfying $1 \leq t^{\prime} \leq t ; C E C_{t}$ and $C E N_{t}$ are cost for coal and nature gas supply in period $t\left(\$ 10^{3} / \mathrm{TJ}\right)$, respectively; $C I E_{t}$ are cost for imported electricity supply in period $t\left(\$ 10^{3} / \mathrm{GWh}\right)$, respectively; $U P_{i t} \quad(i \geq 3)$ are available amounts of hydropower, wind power, solar power and nuclear power in period $t\left(10^{3} \mathrm{TJ}\right)$, respectively; $C V_{i t}$ is operating cost of power conversion technology $i$ for electricity generation in period $t\left(\$ 10^{3} / \mathrm{GWh}\right) ; C S_{o t} C N_{p t}$ and $C P_{q t}$ are unit operating cost of controlling $\mathrm{SO}_{2}, \mathrm{NO}_{\mathrm{x}}$ and $\mathrm{PM}$ emissions during period $t$, (\$/tonne), respectively; $S T_{i t}$ is average service time of power conversion technology $i$ in period $t(\mathrm{~h}) ; V_{t}$ is peak load demand in period $t(\mathrm{GW}) ; A_{i t}$ and $B_{i t}$ are fixed-charge and variable cost for capacity expansion of power conversion technology $i$ in period $t\left(\$ 10^{6}, \$ 10^{6} / \mathrm{GW}\right)$, respectively; $R C_{i}$ is the existing capacity of conversion technology $i$ $(\mathrm{GW}) ; F E_{i t}$ is the units of energy consumption per units of electricity production for power conversion technology $i$ in period $t(\mathrm{TJ} / \mathrm{GWh}) ; M_{i t}$ is variable upper bounds for capacity expansion of power conversion technology $i$ in period $t(\mathrm{GW}) ; I N S_{i b} I N N_{i t}$ and $I N P_{i t}$ are units of $\mathrm{SO}_{2}, \mathrm{NO}_{\mathrm{x}}$ and $\mathrm{PM}$ emission per unit of electricity production for power conversion technology $i$ in period $t$ (tonne/GWh), respectively; $\tilde{\eta}_{o}, \tilde{\eta}_{p}$ and $\tilde{\eta}_{q}$ are the average efficiency of $\mathrm{SO}_{2}, \mathrm{NO}_{\mathrm{x}}$ and PM control measure (\%), which are expressed as the triangular fuzzy sets, respectively; $E S_{t}, E N_{t}$ and $E P_{t}$ are the emission allowance of $\mathrm{SO}_{2}, \mathrm{NO}_{\mathrm{x}}$ and $\mathrm{PM}$ in period $t$ (tonne), which are expressed as the triangular fuzzy sets, respectively; $\tilde{\alpha}_{l}$ is design safety factors assuring the electricity demand can be satisfied completely during period $t$, which are expressed as the triangular fuzzy sets; $\tilde{d}_{t}$ is the total electricity demand during period $t\left(10^{3} \mathrm{GWh}\right)$, which are expressed as the triangular fuzzy sets; $\tilde{d}_{t}$ is the total electricity demand during period $t\left(10^{3} \mathrm{GWh}\right)$, which are expressed as the triangular fuzzy sets; $\operatorname{Pos}\{\cdot\}$ denotes possibility of events in $\{\cdot\}$ where $\beta_{l}$ is a predetermined confidence level and $l$ is type of confidence levels; $X C_{t}$ and $X G_{t}$ are supply amounts of the coal and natural gas in period $t(\mathrm{TJ})$, respectively; $X E_{t}$ is the imported electricity supply in period $t$ $\left(10^{3} \mathrm{GWh}\right) ; X W_{i t}$ is electricity generation amounts of power conversion technology $i$ during period $t\left(10^{3} \mathrm{GWh}\right) ; X_{i t}$ is continuous variables about the amount of capacity expansion of power conversion technology $i$ in period $t(\mathrm{GW}) ; Y_{i t}$ is the binary variables for identifying whether or not a capacity expansion action of power conversion technology $i$ needs to be undertaken in period $t ; X S_{i o t}, X N_{i p t}$ and $X P_{i q t}$ are the $\mathrm{SO}_{2}, \mathrm{NO}_{\mathrm{x}}$ and $\mathrm{PM}$ amount generated from power conversion technology $i$ to be treated by control measure $o$, $p$ and $q$ in period $t$ (tonne), respectively.

\section{Results and discussion}

Figure 1 shows the model solutions for the supplied amounts of coal and gas. It is indicated that the temporal and spatial variations of electricity demand may result in varied energy supply schemes. As the electricity demand increases, the supplied amounts of the coal and natural gas would increase over the three planning periods, and the supplied amounts of the coal are higher than those of the natural gas. It is also found that there is no need to import 


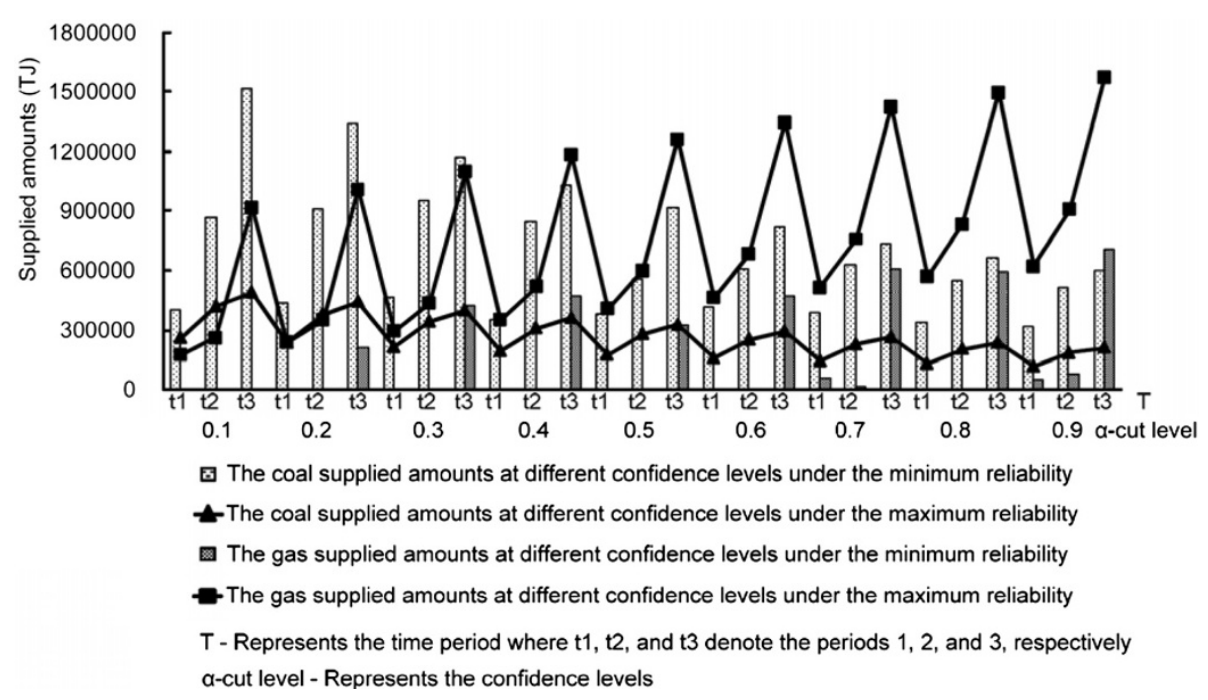

Figure 1 Solutions of coal and gas supplied amounts.

electricity from other regions. For example, at a confidence level of 0.4 with the minimum reliability, the amounts of coal supply are $351.69,851.52$ and $1033.97 \times 10^{3} \mathrm{TJ}$ over the three planning periods, respectively; the supplied amounts of natural gas are 0,0 and $471.98 \times 10^{3} \mathrm{TJ}$, respectively. This is because the coal owns the lowest unit supply cost (i.e. $31.25,37.20$ and $43.05 \times 10^{3} \$ / \mathrm{TJ}$ ), the natural gas ranked in the middle (i.e. 57.50, 62.70 and $\left.67.80 \times 10^{3} \$ / \mathrm{TJ}\right)$, and the imported electricity is the highest (i.e. 900,1000 and $1100 \times 10^{3} \$ / G W h$ ). Figure 2 shows the solution of electricity generation amounts. For the renewable energy, the electricity generation amounts by the hydropower are 22.50, 22.78 and 23.08 GWh over the three planning periods, respectively. Those by the windpower are $12.00,12.00$ and $12.00 \mathrm{GWh}$ over the three planning periods, respectively. This is due to the fact that the hydropower has the highest existing capacity, and the lowest fixed and variable costs for capacity expansion among all renewable energy sources.

From Figures 1 and 2, the solutions of decision variables have notable variations at different $\alpha$-cut levels with two reliability scenarios. The supplied amounts of the coal with the maximum reliability are in a decreasing trend when the $\alpha$-cut level is increasing. Compared with those of the coal, the supplied amounts of the natural gas would increase with the increase of the $\alpha$-cut level. This is because, when the confidence level increases, the electricity demand would increase according to fuzzy algorithm rule (Fiedler et al. 2006); meanwhile, the constraints of the environmental emission standards would become stricter. This will lead to the decrease of the coal supplied amounts, which are deciding factor for pollutant emissions. At the same time, the supplied amounts of the natural gas with low pollutant emissions would increase. This reflects the trade-off between system economy and reliability. A lower system cost would be incurred if a larger quantity of pollutant emission is allowable; meanwhile, the planning scheme with a higher cost would urge the environmental quality maintain at a higher level.

The variation trend of the solutions under the minimum reliability is generally similar to those under the maximum one, except for a few inconsistent points. For example, in period 3, the supplied amounts of the coal are $1520.76,1345.90,1173.80,1033.97,918.11,820.54$, $737.25,665.32$ and $602.57 \times 10^{3} \mathrm{TJ}$, respectively; those of the natural gas are $0,213.41,423.83,471.98,328.16$, $473.37,606.19,594.80$ and $710.26 \times 10^{3}$ TJ, respectively. The supplied amounts of the natural gas at the confidence levels of 0.5 and 0.8 in period 3 are not consistent with the general changing trend, as are the cases for a number of solutions of coal in periods 1 and 2. This is mainly due to the complex interactive relationships among various components of the planning system. Another reason may be the loose constraints incurred by the setting of minimum reliability, making the effect of confidence levels become less significant. In addition, at the same $\alpha$-cut levels, the supplied amounts of the coal under the minimum reliability are higher than those under the maximum one; for natural gas, the varying trend is opposite. This is due to the fact that the minimum reliability prefers looser environmental emission standards and lower electricity demand than the maximum reliability does. Therefore, the energy source of coal would become more popular than the natural gas.

The optimal treatment amounts of pollutants can be generated from various conversion technologies under two reliability levels. The solution indicates that the increase of the coal and natural gas amounts would result in 

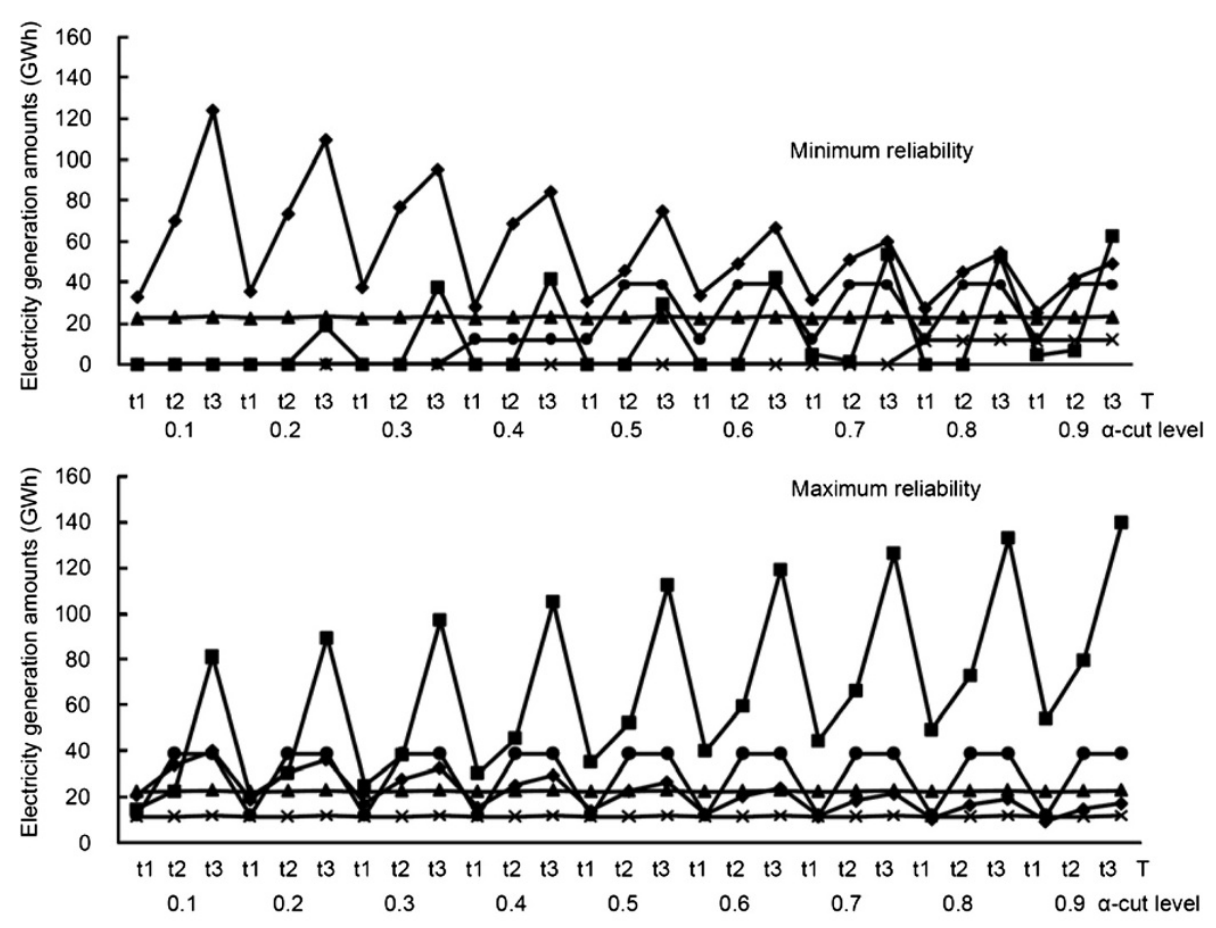

The electricity generation amounts of the coal under the two reliability scenarios
- The electricity generation amounts of the gas under the two reliability scenarios
- The electricity generation amounts of the hydropower under the two reliability scenarios
T- Represents the time period where $t 1$, t 2 , and $\mathrm{t} 3$ denote the periods 1,2 , and 3 , respectively
a-cut level - Represents the confidence levels

Figure 2 Solutions of electricity generation amounts.

an increased amount of pollutant reduction. For example, the disposal amounts of $\mathrm{SO}_{2}$ generated from the coal-fired power conversion technology by SAS over the three planning periods are $0,170.25$ and $243.56 \mathrm{t}$, respectively; the allocated amounts of $\mathrm{NO}_{\mathrm{x}}$ to the SCR technology are 0 , 49.61 and $62.89 \mathrm{t}$, respectively; the treated amounts of PM to the $\mathrm{BH}$ technology are $13.47,55.92$ and $67.25 \mathrm{t}$, respectively. Generally, the varying trends of the pollutant treatment amounts were similar to those of the supplied amounts for the emission sources. When the confidence level increases, the treated amounts of $\mathrm{SO}_{2}$ from coal would generally decrease. For example, under the minimum reliability, at the period 3 , the treated amounts by SAS at the different confidence-levels are 459.86, 390.28, 310.01, 243.56, 186.98, 140.01, 99.44, 61.14 and $31.88 \mathrm{t}$, respectively; those by the LSD are $529.26,485.10,453.44$, $428.94,410.16,393.68,380.07,371.59$ and $360.03 \mathrm{t}$, respectively. The reason is that, when the confidence level goes higher, the constraints of the environmental standards would become stricter; this would lead to reduced supplied amounts of the coal, and consequently decreased emission levels of the pollutants. Meanwhile, over the three planning periods, the treated amounts of the coal by SAS are lower than those by LSD, due to its higher operational cost. Similar trends can also be found for the pollutants generated from the natural gas.

The total costs at different $\alpha$-cut levels also vary with reliabilities. As the $\alpha$-cut level increases, the electricity supply would increase, leading to better environmental quality; however, the related system cost would increase. The system cost with the minimum reliability would be lower than that with the maximum one, indicating that a lower system cost is related to a higher environmental risk. A conservative alternative is more effective to meet the electricity requirement and maintain the environmental quality. A trade-off between the total system cost and reliability of satisfying model constraints needs to be analyzed in order to gain an in-depth insight into the characteristics of energy planning systems.

\section{Conclusions}

A double-sided fuzzy chance-constrained mixed-integer programming (DFCCMIP) model was developed in this study and applied to a regional energy systems planning 
problem. The model coupled DFCCP and MIP models into a general framework, and could help deal with uncertainties expressed as fuzzy sets associated with both the left- and right-hand-side components of constraints, and the capacity expansion issue of energyproduction facilities. The study results indicated that DFCCMIP allowed violation of system constraints at specified confidence levels with various reliability scenarios. The solutions of continuous and binary variables could help decision makers establish various energy production patterns and capacity-expansion plans under complex uncertainties, and gain in-depth insights into the trade-offs between system economy and reliability.

\section{Competing interests}

The authors declared that they have no competing interest.

\section{Acknowledgement}

This research was supported by Earth Observatory of Singapore (EOS) Project (M4080891.B50) and Singapore's Ministry of Education (MOM) AcRF Tier 1 Project (M4010973.030).

\section{Author details}

${ }^{1}$ School of Civil \& Environmental Engineering, Nanyang Technological University, 50 Nanyang Avenue 639798 Singapore. ${ }^{2}$ Earth Observatory of Singapore (EOS), Nanyang Technological University,

50 Nanyang Avenue 639798 Singapore. ${ }^{3}$ S-C Research Academy of Energy \& Environmental Studies, North China Electric Power University, Beijing 102206, China. ${ }^{4}$ DHI-NTU Water \& Environment Research Centre and Education Hub, Nanyang Technological University, 50 Nanyang Avenue 639798, Singapore.

\section{Authors' contributions}

QXS is responsible for the development of the energy systems planning model and drafted the manuscript. XY participated in model computation, and involved in result analysis. YJJ participated in the model development, and helped polish the manuscript. All authors read and approved the final manuscript.

Received: 13 June 2012 Accepted: 14 August 2012

Published: 14 August 2012

\section{References}

Cai YP, Huang GH, Yang ZF, Lin QG, Tan Q (2009) Community-scale renewable energy systems planning under uncertainty-An interval chance-constrained programming approach. Renew Sustain Energy Rev 13:721-735

Cao CW, Gu XS, Xin Z (2009) Chance-constrained programming models for refinery short-term crude oil scheduling problem. Appl Math Model 33:1696-1707

Fiedler M, Nedoma J, Ramík J, Rohn J, Zimmermann K (2006) Linear optimization problems with inexact data. Springer-Verlag, New York

Huang GH, Baetz BW, Patry GG (1995) Grey integer programming: an application to waste management planning under uncertainty. Eur J Oper Res 83:594-620

Li YF, Li YP, Huang GH, Chen X (2010) Energy and environmental systems planning under uncertainty - An inexact fuzzy-stochastic programming approach. Appl Energ 87:3189-3211

Lin QG, Huang GH (2009) Planning of energy system management and GHGemission control in the Municipality of Beijing-An inexact-dynamic stochastic programming model. Energy Policy 37:4463-4473

Liu BD, Iwamura K (1998) Chance-constrained programming with fuzzy parameters. Fuzzy Set Syst 94:227-237

Liu L, Huang GH, Fuller GA, Chakma A, Guo HC (2000) A dynamic optimization approach for nonrenewable energy resources management under uncertainty. J Petrol Sci Eng 26:301-309 doi:10.1186/2193-2697-1-6

Cite this article as: Qin et al: Confidence modeling with reliability: a systems approach to sustainable energy planning. Environmental Systems Research 2012 1:6.

\section{Submit your manuscript to a SpringerOpen ${ }^{\odot}$ journal and benefit from:}

- Convenient online submission

- Rigorous peer review

- Immediate publication on acceptance

- Open access: articles freely available online

- High visibility within the field

- Retaining the copyright to your article

Submit your next manuscript at $\boldsymbol{~ s p r i n g e r o p e n . c o m ~}$ 